\begin{tabular}{l|l} 
REVISTA & $\begin{array}{l}\text { Revista Educación } \\
\text { ISSN: } 0379-7082 \\
\text { ISSN: 2215-2644 } \\
\text { revedu@gmail.com } \\
\text { Universidad de Costa Rica } \\
\text { Costa Rica }\end{array}$
\end{tabular}

\title{
El verso aventurero de Emma Gamboa, poesía infantil de la maestra, pedagoga y escritora
}

Rubio Torres, Carlos

El verso aventurero de Emma Gamboa, poesía infantil de la maestra, pedagoga y escritora

Revista Educación, vol. 46, núm. 1, 2022

Universidad de Costa Rica, Costa Rica

Disponible en: https://www.redalyc.org/articulo.oa?id=44068165041

DOI: https://doi.org/10.15517/revedu.v46i1.49661

\section{(c) $(1) \Theta$}

Esta obra está bajo una Licencia Creative Commons Atribución-NoComercial-SinDerivar 3.0 Internacional. 


\title{
El verso aventurero de Emma Gamboa, poesía infantil de la maestra, pedagoga y
} escritora

\author{
The Adventurous Verse of Emma Gamboa: Poet, Children's Poetry by the Teacher, Pedagogue and Writer \\ Carlos Rubio Torres \\ Universidad de Costa Rica, Costa Rica \\ carlos.rubio@ucr.ac.cr \\ DOI: https://doi.org/10.15517/revedu.v46i1.49661 \\ Redalyc: https://www.redalyc.org/articulo.oa?

iD https://orcid.org/0000-0002-6175-1401

\section{RESUMEN:}

Es este ensayo se reflexiona sobre la poesía infantil de Emma Gamboa Alvarado (1901-1976), por ello, se indaga en algunos textos literarios que nutrieron su trabajo, como los creados por costarricenses: Omar Dengo, Joaquín García Monge, Roberto Brenes Mesén y Carmen Lyra; así como voces extranjeras: José Martí, Gabriela Mistral, Claudia Lars, Rabindranath Tagore y Walt Whitman. Se presentan postulados, propuestos por Gamboa, sobre la democratización de la lectura, surgidos con motivo de la organización de la Primera Feria Nacional del Libro llevada a cabo en Costa Rica en 1954. Se estudia, asimismo, una poética de su trabajo, sustentada en sus artículos literarios y entrevistas que le hicieron, y se contrasta con posturas teóricas de su tiempo y la actualidad, con el fin de recomendar la reedición de su obra, principalmente aquella que dirigió a la niñez.

Palabras clave: Poesía, Literatura Latinoamericana, Infancia, Educación Artística, Folclor.

\begin{abstract}
:
This essay is a reflection on the poetry of Emma Gamboa Alvarado (1901-1976), with a specific emphasis on children's poetry. It also explores literary texts that influences her work, most written by Costa Ricans, such as Omar Dengo, Joaquín García Monge, Roberto Brenes Mesén and Carmen Lyra. The foreign voices of José Martí, Gabriela Mistral, Claudia Lars, Rabindranath Tagore and Walt Whitman were also influential. As a result, Gamboa proposed the idea of the democratization of reading while organizing the First Costa Rican Book in 1954. Literary articles and interviews regarding the author's poetry were also used and contrasted with theoretical positions of her time as well as the present day. A recommendation is made to reprint the work of this author to foster knowledge of her poetry, particulary that aimed at children.
\end{abstract}

KEYWORDS: Poetry, Latin American Literature, Childhood, Arts Education, Folklore.

\section{INTRODUCCIÓN}

Consagrada su vida a la educación, Emma Gamboa (1901-1976) se distinguió desde su juventud por entregarse con denuedo, estudio, sagacidad y un profundo sentido innovador a su condición de maestra. Como si se tratara de un apostolado, ejerció la docencia en diferentes niveles, del preescolar al universitario.

Nacida en San Ramón, Alajuela, Costa Rica, inició sus estudios profesionales en la Escuela Normal, situada en Heredia y conquistó los títulos de bachillerato, maestría y doctorado en la Universidad de Ohio, Estados Unidos. Fue, asimismo, una mujer que impactó las políticas públicas nacionales pues fundó, junto a otras personas, la Asociación Nacional de Educadores (ANDE), forjó una moderna Facultad de Educación en la naciente Universidad de Costa Rica (UCR), luchó por la autonomía universitaria, se empecinó en crear una Escuela Laboratorio que sirviera como semillero para la continua experimentación educativa con un profundo sentido humanístico, realizó estudios y ensayos de carácter filosófico y pedagógico, escribió libros de texto iniciadores en la lectoescritura con los que se formaron varias generaciones, ejerció como decana de la Facultad de Educación y fue la primera mujer costarricense que ocupó el cargo de Ministra de Educación Pública, sin embargo, se ha estudiado poco su condición de poeta, de artista que realizó una prolífica obra literaria, en gran medida, orientada a la niñez, tal como lo indican Gamboa de Murillo (1990) y Dengo (2011). 
Estos poemas se encuentran dispersos en revistas y periódicos como Repertorio Americano, Farolito, Costa Rica de ayer y hoy, Revista de la ANDE y La Nación; en estudios y antologías como Literatura infantil costarricense de Luis Ferrero (1958), Cultivo una rosa blanca de Alfonso Chase (1988) o Por quécuento y canto para mis niños de Margarita Dobles (1991); en los libros que la autora preparó con fines didácticos en los que, como se tratará más adelante, no se abandona el cuidado literario, como la colección Versos para niños (1941), en la que reúne composiciones de varios poetas, y Canciones para niños (s.f.), en la que colecciona piezas musicales con sus respectivas partituras; los libros dedicados a la lectoescritura: Paco y Lola (1960b) y La casita del monte (1980), así como dos libros literarios, dos de ellos destinado a la niñez llamados El sombrero aventurero de la niña Rosaflor (1969) y en la recopilación póstuma Flor de infancia (1978) y un libro orientado al público adulto que contiene algunos poemas que perfectamente podrían encajar con el canon de la literatura infantil, titulado Instante de la rosa (1977).

Casi toda esta producción se inscribe en el género de la poesía; sin embargo, en $L$ a casita del monte (1980) se encuentran textos que podrían ser descritos como poemas en prosa y tan solo ha sido posible hallar un cuento: San Nicolás y la niña que no se quería dormir (Gamboa, 1955), presentado como un arreglo de un texto proveniente del idioma inglés; si bien presenta los apuros a los que se ve sometido el santo para dejar sus obsequios a una pequeña insomne en la nochebuena, sus personajes se comunican por medio de versos musicalizados, por lo que esa condición evidencia que la escritora no abandona la poesía.

Sirva este ensayo para reivindicar el papel de Emma Gamboa en las letras costarricenses y reflexionar sobre las lecturas con las que nutrió su creación literaria, su posición sobre la promoción de la lectura con una visión democrática y el ideario poético que sostuvo, de manera ininterrumpida, desde inicios de la década del 30 hasta su fallecimiento, ocurrido en 1976. Para lograrlo, se leen críticamente sus composiciones, las opiniones vertidas en artículos, ensayos y entrevistas, y algunas de las obras literarias a las que ella se refirió a lo largo de su vida.

La infancia de esta mujer transcurrió, a inicios del siglo XX, en San Ramón, una ciudad a la que tradicionalmente se le ha llamado "cuna de poetas" y que también vio nacer a un creador destacado como Lisímaco Chavarría (1873 - 1913), cuya obra se inscribió en la corriente modernista. Realizó Gamboa sus estudios secundarios en la Escuela Normal, razón por la cual se trasladó a residir en Heredia, donde se encontró con personalidades del contexto artístico, pedagógico y científico nacional, por ello, sin pretender construir una biografía, en las lecturas que pudieron motivarla a elaborar su legado literario.

\section{2. ÉrASE UNA NiÑa QUE AMABA LOS LIBROS}

En el aula escolar, la pequeña Emma demostró gran facilidad para la comprensión lectora y las matemáticas, narra Gamboa de Murillo (1990). A pesar de ello, no le gustaban otras asignaturas, pues alguna vez se escondió sobre el techo de su casa para no asistir a la clase de costura. De esa época, trae a la memoria a su maestra de primeras letras, Oliva de Zamora, a quien le dedica el poema "La niña Oliva", que se encuentra registrado en Instante de la rosa. En ese texto poético presenta a la docente que "escapó de la prosa del silabario" (Gamboa, 1977, p. 34), como un hada madrina que la hizo encontrarse con múltiples textos literarios como La Cenicienta, La Bella y la Bestia, Pulgarcito, el cuento "De los Apeninos a los Andes" del libro Corazón de Edmundo de Amicis y personajes bíblicos como Jacob y Ruth la Moabita, pues, tal como apuntaba Mistral (2010): "Escrituras sacras, todas, una por una y nuestra Biblia la primera valen, por el más ancho poema épico, en resuello heroico" (p. 578). No satisfecha con ello, explica Gamboa de Murillo (1990) que, debido a la limitada situación económica de la familia, leyó muchos libros prestados. A pesar de que el padre de la niña abandonó el hogar para encontrar mejor fortuna en las llamadas minas de Abangares, le obsequió una pequeña biblioteca, pues eso era lo que más deseaba.

Con el apoyo de una beca, Emma ingresó a la Escuela Normal de Costa Rica, situada en Heredia, donde obtuvo, con singular éxito, su título de maestra. También, en esa institución, recibió lecciones con destacadas 
figuras de la literatura, el arte, la pedagogía y las ciencias, como los directores Roberto Brenes Mesén, Joaquín García Monge, Carlos Gagini y Omar Dengo; docentes como el poeta Luis Roberto Flores, el músico y compositor José Joaquín Vargas Calvo; los literatos Luis Dobles Segreda y Rómulo Tovar; el científico y escritor Anastasio Alfaro; la autora Carmen Lyra; el lingüista Cristian Rodríguez; y los pedagogos Luis Felipe González Flores, José Guerrero Arguedas, Tranquilino Sáenz y Salvador Umaña.

Para comprender la escritura literaria de Emma Gamboa es esencial estudiar el sitio que daban a la literatura algunas personas que le ofrecieron lecciones en la Escuela Normal y la apreciación con que ella retribuyó esa formación.

\section{DE VOCES MAESTRAS NACEN LOS VERSOS}

Bajo la dirección de Omar Dengo se realizaron veladas en la Sala Magna de la Escuela Normal (la cual tiene un diseño arquitectónico propio de un teatro), en la que estudiantes y docentes ejecutaban obras dramáticas o conferencias con disertantes como Jacinto Benavente, Premio Nobel de Literatura. Dengo también escribió valiosas páginas literarias y dio un sitio especial a la recitación de la poesía; este intelectual guardó admiración por la propuesta escénica de la actriz y recitadora rusa argentina Berta Singerman, quien se presentó en el Teatro Nacional de Costa Rica en varias ocasiones y a quien le dedicó una elogiosa composición en la que expresó: "Bendita sea esa voz en cuya presencia se viven las ansiedades infinitas de la aurora. / iQue se extienda por lo azul y sea su ensueño una nueva complacencia de los dioses en el amor de la Belleza!” (Dengo, 1961, p. 102); por ello no es de extrañar que la poesía infantil de Gamboa no solo se pueda leer silenciosamente, pues parece ser escrita para ser expresada en voz alta. Gamboa exaltó las utilidades de la poesía coral en la escuela y señaló que es "un recurso excelente de expresión y goce estético. Aún los niños tímidos entran en el contagio de lo bello cuando participan en un grupo coral”, (Gamboa, 1965, p. 82). Un ejemplo de ello es el poema Gracielina (Gamboa, 1954) que también fue danzado a manera de un ballet, tal como se consigna en la revista Farolito, en la que aparece esa composición literaria acompañada de una fotografía de la niña Estrella Quirós, quien, ataviada como una bailarina clásica, interpreta a Gracielina.

El fervor de Dengo por la literatura quedó plasmado en un ensayo escrito por Emma Gamboa, en el que acotó que sus lecciones no solo eran profusamente documentadas, pues "no faltaban escritores de la calidad fina de un Rabindranath Tagore en la bibliografía que consultan los alumnos" (Gamboa, 1971, p. 46) y agrega que la poesía de este escritor hindú se leía junto a las obras de Gabriela Mistral o León Tolstoi.

Otro maestro de Emma Gamboa fue Joaquín García Monge, quien publicó el periódico Repertorio Americano, a partir de 1919 y hasta su fallecimiento ocurrido en 1958. Debe acotarse que García Monge, junto a Carmen Lyra, crearon la Cátedra de Literatura Infantil en la Escuela Normal de Costa Rica, tal como lo señala Rubio (2021), y que en esas lecciones, aparte de tratar libros considerados clásicos, se le daba prioridad al folclor. Se dio énfasis a las cántigas, las rondas, las adivinanzas, los cuentos populares o las leyendas como textos fundamentales en el proceso de formación de lectura de la niñez. Precisamente, Emma Gamboa tomó el folclor como punto de partida de muchos de sus poemas, no solo porque compuso canciones que parecen creadas para ser interpretadas al tomarse de las manos y danzar en ronda, como lo expresa su colección de Canciones para niños: “-Hola, feliz Rosina, / hola, ¿qué traes ahí? // -Dalias, rosas / y flor de jazmín / traigo en mi falda / todo el jardín." (Gamboa, s.f., p. 3). O en su poema "Hormiguita" (1932), en el que narra, de manera versificada, el cuento del mismo nombre que la escritora andaluza Fernán Caballero (1988) había recopilado de la tradición popular y fue incluido en su obra Cuentos de encantamiento; asimismo, debe acotarse que Gamboa (1960b) realizó otra versión del mismo poema, con el título Hormiguita y Ratón Pérez, que incluyó en su libro didáctico para primer grado Paco y Lola. Carmen Lyra publicó otra versión de esa historia con el título "La Cucarachita Mandinga" en Los cuentos de mi tía Panchita (1920), obra que salió a la luz pública por vez primera bajo los cuidados editoriales de García Monge. 
Fue tal la devoción de Emma Gamboa por el maestro don Joaquín, como solía llamarlo, que le dedicó un poema fechado en 1945, en cuyos versos se lee: "Le gusta andar acompañado. / A veces viene con Martí, el Arcángel, / o según sus palabras, 'con el santo patrón de América'. / Predica la pedagogía teresiana de Gabriela" (Gamboa,1958); lo publicó a propósito del fallecimiento del creador de Repertorio Americano, sobre quien, en ese mismo poema, expresó: "Hablemos de don Joaquín, el nuestro. / No el internacional de Repertorio / sino el que conversa con nosotros" (p. 4).

Carmen Lyra fue encomendada por Joaquín García Monge para asumir la Cátedra de Literatura Infantil, para de esa manera iniciar a la juventud que se formaba en la Escuela Normal, en la admiración por obras registradas entonces como clásicos que podía leer la niñez y en encontrar el valor de las expresiones folclóricas de Costa Rica y países extranjeros, ya sea en lengua española o con versiones provenientes de otros idiomas y vueltas a decir en la lengua materna. Por eso, no es de extrañar que, en la época en la que Emma Gamboa se formaba como maestra, Lyra haya publicado la primera edición de Los cuentos de mi tía Panchita. A pesar de que, en años posteriores, ambas mujeres hayan abrazado posiciones políticas e ideológicas opuestas, Gamboa reconoció por escrito el valor literario de la obra de su maestra. En la presentación del libro Cuentos viejos de María Leal de Noguera, cuya primera edición salió a la luz pública en 1923, se encuentra un preámbulo en el que resaltó el valor del folclor en la formación literaria de las jóvenes generaciones, pues argumentó que tanto Leal de Noguera como Lyra resguardaron el acervo de los cuentos populares y que la escritora de Los cuentos de mi tía Panchita ostentó "el gracejo y la agudeza de los contadores de velada que alientan el buen humor con los relatos de desenfado gracioso y originalísima gracia picaresca” (Gamboa, 1992, p. 11).

Roberto Brenes Mesén fue otro maestro y también poeta que ofreció clases en la Escuela Normal a Emma Gamboa, tal como lo registró Gamboa de Murillo (1990), dio fe de su dedicación al estudio, ya que después de compartir por primera vez en el aula, acudió a la oficina de Dirección y afirmó que de San Ramón les había llegado una maravilla. Tal como describió Dengo (2011), en ese centro educativo, desarrollado como un proyecto pedagógico vanguardista de formación docente, la joven Gamboa participó de experiencias literarias, dio sus primeros pasos en la escritura poética, inició el liderazgo que la caracterizó en las múltiples facetas de su vida y conoció textos que resultan fundamentales para comprender su elaboración poética.

José Martí fue evocado constantemente por Gamboa. El pensador cubano defendió el derecho absoluto de la niñez a la sabiduría, expresada con sencillez y sentido estético, pues tal como lo escribiera en la introducción al primer número de la revista La Edad de Oro: "Todo lo que quieran saber les vamos a decir, y de modo que lo entiendan bien, con palabras claras y con láminas finas” (Martí, 2010, pp. 5-6). Debe comprenderse que García Monge publicó, en un solo volumen, los cuatro números de La Edad de Oro en 1921, hecho confirmado gracias a un hallazgo realizado por el Dr. Marcelo Bianchi Bustos en Buenos Aires, Argentina (M. Bianchi Bustos, comunicación personal, 17 de agosto de 2021).

Inmensa fue la admiración de Gamboa por Martí, por ello le dedicó un poema en el que asegura: "Los niños y los hombres que escuchan a Martí sienten como una estrella en el corazón: es la estrella de los hombres buenos y los héroes" (Gamboa, 1953, p. 5). Con absoluta congruencia, la educadora costarricense encontró los ideales martianos de fraternidad, belleza, dignidad y libertad en otros personales, por eso escribió otras composiciones como la que dedicó al expresidente Juan Rafael Mora, titulada "Don Juanito" (Gamboa, 1956), publicada en la revista Farolito en el año del centenario de su gesta heroica, posteriormente reproducida por Ferrero (1958) en Literatura infantil costarricense y en el libro Flor de infancia (Gamboa, 1978).

Innegable la presencia de Gabriela Mistral en los planteamientos literarios (y también pedagógicos, aunque no se desarrolle ese tema en este ensayo) de la obra de Emma Gamboa. Fue la llamada Maestra de América, nacida en Chile, y quien planteó la necesidad sempiterna de que docentes narren cuentos y reciten poemas a la niñez y otorguen un papel protagónico al folclor como parte fundamental de su trabajo. Escribía al respecto: “...no daría título de maestro a quien no contase, con dicha, con frescura y hasta alguna fascinación”, (Mistral, 2011, p. 231). Bien se sabe que la reconocida escritora universalizó rondas y canciones de cuna, cuyo 
ritmo y lengua evocan voces anónimas del folclor, basta leer, por ejemplo: "Duérmete mi niño / duérmete sonriendo, / que es la ronda de astros / quien te va meciendo.” (Mistral, 1926, p. 199). En sus libros dedicados al aprendizaje de la lectoescritura, Emma Gamboa también incluyó rondas y canciones de cuna, en las que se hizo notorio el uso del metro y la musicalidad. Escribió, por ejemplo, “Arrurrú niñito, / arrurú, arrorró, / duerme ya mi niño, / duerme ya mi amor." (Gamboa, 1962, p. 68).

Amor demostró Emma Gamboa por el ideario educativo y poético de Gabriela Mistral. Cuando falleció esta mujer, ganadora del Premio Nobel de Literatura en 1945, la maestra costarricense recordó la única visita que realizó al país, invitada por García Monge, en 1931. La memoria, entonces, la hizo recrear esos días que, al parecer, resultaron imperecederos: "Habían hecho un sendero con ramillos de reseda y sobre aquella fragancia pasó la maestra de América con su traje sencillo y sus medias de algodón.” (Gamboa, 1957, p. 5) y describió ese encuentro, al parecer casual, con María Teresa Obregón, su pequeña hija María Eugenia Dengo, Carlos Luis Sáenz y Francisco Amighetti. Así, afirmó que Gabriela se asemejaba a una mujer bíblica y que, a pesar de que su voz grave ya era solo una reminiscencia, el dulzor de su sabiduría permanecía firmemente.

Entre las incontables lecturas poéticas y literarias que pudo haber hecho Emma Gamboa, se encuentra la poeta salvadoreña Claudia Lars, tal como afirmó en una entrevista ( No estamos mal en literatura infantil, 1975). Coincidieron en doctrina y en el sentir del rescate del folclor como fuente primigenia y dadora del ritmo; coincidieron, también, en el hecho de no creer que la niñez, a pesar de la breve edad, tiene el derecho de conocer textos de alta calidad, escritos con sentido estético y pletóricos de inteligencia. Al respecto, esta escritora centroamericana consideraba: "Sostengo que quien escribe para niños debe tener como primer atributo el don de la poesía. Aunque escriba prosa. Solo el poeta puede visitar el jardín de los ángeles”, (Lars, 1987, p. 10). Gamboa, al igual que ella, no abandonó la poesía, ni siquiera en aquellos libros escritos con un riguroso criterio científico, con el objetivo de iniciar a la persona en los ejercicios de la lectura y la escritura.

Señaló Dengo (2011) que Emma Gamboa leyó, con fervor, a Rabindranath Tagore, especialmente su poema Ofrenda lírica. A pesar de ello, se podría decir que la maestra costarricense se mantuvo fiel al postulado que el poeta hindú, quien escribía, en el año 1892, en su libro Entre-visiones de Bengala:

Si yo no hubiera oído cuentos de hadas ni leído "Las mil y una noches" y "Robinson Crusoe" en la infancia, estoy seguro de que las riberas lejanas o el lado más distante de los anchos campos, no me habrían conmovido así; el mundo entero, a decir verdad, hubiera tenido sentido diferente para mí. (Tagore, s.f., p. 57)

Walt Whitman fue otro poeta que particularmente leyó Gamboa, tal como lo expresó Dengo (2011), especialmente el poema «El trompetero místico». Al igual que el vate de Norteamérica, la maestra Emma no ofreció respuestas centradas en la visión adulta cuando en el poema 6 de Canto de mímismo, un niño preguntó “Qué es la hierba?” (Whitman, 1975, p. 61). El escritor parece responder que tampoco lo sabe, y confiado en el sentido místico que lo acompañó toda la vida, no solo motivado por las lecturas bíblicas, sino también por la guía de Krishnamurti, le responde, imagina que la hierba es "el pañuelo de Dios” (Whitman, 1975, p. 61).

Se evidencia así que Emma Gamboa se esforzó, a lo largo de su vida, por lograr que la población costarricense se solazara con la literatura y reafirmara, de manera autónoma, su gusto por la lectura; de ello se registran argumentos en la inauguración de la Primera Feria Nacional del Libro, llevada a cabo en 1954.

\section{LA LECTURA, DERECHO DE UN PUEBLO DEMOCRÁtico}

Mucho más que una feria, la experiencia desarrollada por la Dra. Emma Gamboa, en su calidad de decana de la Escuela de Pedagogía de la UCR, en 1954, fue una oportunidad para reflexionar sobre la necesidad de fomentar la lectura en el pueblo costarricense y recordarle al Estado, principalmente al Poder Ejecutivo, su responsabilidad en ese papel.

La expectativa sobre esta feria se generó meses antes de su inicio, tal como se colige de un artículo anónimo (ElEjecutivo se comprometió a dar impulso a las Bibliotecas Escolares, 1954), en el que informa que la Escuela 
de Pedagogía hace un llamado al presidente de la República, José Figueres Ferrer, para iniciar una cruzada por la alfabetización de quienes saben leer y se registran declaraciones de Emma Gamboa con el anuncio de la creación de un Centro Martiano (honor a José Martí) y la Asociación Costarricense de Bibliotecarios, bajo la dirección de Julián Marchena, quien en ese entonces era director de la Biblioteca Nacional.

Se inauguró esta feria el 24 de agosto de 1954 y se llevó a cabo en las instalaciones que, a la sazón, ocupaba la Escuela de Pedagogía, en el inmueble que otrora perteneció a la Universidad de Santo Tomás, diagonal al Teatro Nacional de Costa Rica, en San José. Aparte de la facultad mencionada, participaron el Consejo Universitario y la Biblioteca de la UCR, la Biblioteca Nacional, casas editoras, librerías y organizaciones culturales en su planificación. Según se narra en un artículo anónimo (La primera Feria del Libro ser ha interpretado en dimensiones nacionales, 1954), el evento fue interpretado como un acontecimiento de impacto nacional al que asistieron altos funcionarios y funcionarias públicas y representantes de la intelectualidad. En su discurso, la Dra. Gamboa explicó que se realizaba esta actividad bajo el lema que se encontraba inscrito en el escudo de la Universidad de Santo Tomás y que había hecho suyo la entonces joven UCR: Lucem Aspicio - búsqueda de la luz - con el símbolo del girasol de oro, a manera de representación del espíritu que alienta el proyecto de colocar el libro a disposición del público.

La realización de esa primera feria suscitó las meditaciones de la Dra. Gamboa (1954, p. 10), por ello realizó acotaciones sobre lo que hoy se conoce como promoción de la lectura. Con el acostumbrado sentido de argumentación que la caracterizaba, sostenía que la clase económica media de Costa Rica es la que más practicaba la lectura, y, a pesar de ello, carecía del dinero necesario para adquirir libros; aseveró que las personas menos afortunadas no están relacionadas con el mundo bibliófilo porque les resultaba ajeno, como los zapatos que no han aprendido usar y que se encuentran lejanos a su alcance y experiencia. Enunció, con vehemencia, que hacía falta que gente adinerada se desprendiera de bienes superfluos e innecesarios y que, por medio de su generosidad, ayudara y fundaran bibliotecas. Al respecto, señaló que, en ese entonces, el 44 $\%$ de las escuelas costarricenses no poseía un solo libro que no fuera didáctico y solo $4 \%$ tenía un número considerable de volúmenes. Agregó que las bibliotecas públicas eran pocas y que no tenían la capacidad de satisfacer las necesidades de ese déficit cultural.

Se evidenció así que Emma Gamboa consideró que el libro - especialmente la lectura de textos literarios - debería ser derecho del pueblo costarricense, no solo como una forma de hacerse de conocimientos, sino como un camino para adentrarse en el humanismo, la tolerancia, la espiritualidad, la libertad y la comprensión de los sentires de las otras personas, como características indispensables de un pueblo democrático. Por eso, no solo por medio de la Feria del Libro, durante la totalidad de su vida profesional se esforzó por hacer llegar los beneficios de la lectura a la totalidad de la población, sin guardar distinción de ninguna clase, hecho que adquiere certeza al estudiar sus libros didácticos, textos literarios, así como el papel que dio a la Facultad de Pedagogía y la Facultad de Educación de la UCR, o su proyecto de Escuela Laboratorio, como instituciones líderes en los procesos de formación en materia de lectura y escritura.

En ese mismo artículo, publicado en La Nación el 5 de setiembre de 1954, la Dra. Gamboa apoya la postura de Julián Marchena, director de la Biblioteca Nacional y poeta, quien defendió a las bibliotecas, no como organismos desvinculados de las instituciones educativas, sino adheridos a ellas como cuerpos de idéntica sustancia. Por ello, recordó el compromiso asumido por el Sr. José Figueres Ferrer, expresidente de la República, al inaugurar la feria, de fortalecer la Biblioteca Nacional e impulsar otras bibliotecas en el territorio nacional. Por eso, señaló con absoluta autoridad: "La herramienta de trabajo y el libro son las armas de mayor poder porque trabajan de cierto por el hombre y no contra el hombre” (Marchena, citado por Gamboa,1954, p. 10).

Razones suficientes para ahondar en las concepciones que Gamboa tuvo de la poesía y en los beneficios que, desde su perspectiva, propiciaban a la niñez. 


\section{TrAS LA BÚSQUEDA DE UNA POÉTICA}

Como herencia inexorable de su formación inicial en la Cátedra de Literatura Infantil, en la Escuela Normal, Emma Gamboa dio lugar prioritario al folclor en sus composiciones poéticas. Son múltiples los poemas en los que evoca las anónimas canciones de cuna, adivinanzas, trabalenguas o rondas que parecen crear ese ambiente descrito en libros de teoría de la literatura destinada a la niñez de la primera mitad del siglo XX, por ejemplo, Aramburu (1944) decía: “...las mismas rondas con una devoción infatigable y sostenida. Los coros parecían nuevos. Las glosolalias siempre graciosas, la tonada vocal siempre seductora. En el aire quieto, cargado de fragancia, las rimas de los niños tenían un sortilegio sonoro y penetrante"(p. 15). Por ello, la maestra convida al corro de esta manera: "Juguemos a la ronda / ronda de la flor / gira, gira ronda / a lo girasol" (Gamboa, 1962, p. 92). Sobre este mismo tema, Miretti (2004) dice que el folclor es inescindible de la historia de cada persona, retrata su entorno cultural y es fuente primigenia de la literatura destinada a la niñez. En Europa y América, la niñez ha sido arrullada y ha pasado momentos de inexplicable valor lúdico al cantar estos juegos, que, desprovistos de cualquier interés didáctico o moralizante, se convierten en recursos de gozo y sonrisa.

Es esa lectura de poesía la que buscó incansablemente Gamboa, como un texto que la niñez conociera por medio de lo que Bornemann (1977) denominara degustación poética para apreciar toda poesía creada por una persona adulta e intencionalmente destinada a la niñez, o bien, aquella poesía que, a pesar de no haber sido creada intencionalmente para el público infantil, puede ser gozada por cualquier hombre o mujer, sin importar su edad. Este hecho se confirmó por medio de la lectura de algunos poemas que Gamboa incluyó en su libro Instante de la rosa (1977), orientado a mayores, pero que pueden ser leídos y sentidos por una niña o un niño, como sería el caso de No es mío este esplendor: "No es mío, lo sé, / este esplendor de cielo. / Este beso de luz, / un roce de astro, / un destello logrado / por el reflejo. / Pero mi vida sonríe / como un instante / como una madeja de sol / entre los dedos." (Gamboa, compilada por Chase, 1988, p. 185).

Bornemann (1977) incluyó en su teoría sobre poesía infantil la presencia del humor disparatado, el sinsentido, o bien, acudiendo al anglicismo, el nonsense, con el fin de propiciar la alegría y para evadir lo cotidiano, pues la función primordial de quien se considera poeta de la infancia es la de jugar con la niñez y permitir el libre vuelo de la imaginación. Con plena congruencia con esta visión, Gamboa también dio un lugar al humor y al desenfado, como ocurre con la composición El muñeco de maní, incluido en el libro Paco y Lola (1960b), en el que se narró que el muñeco, junto a otros personajes, subió a un tren que terminó cayendo por un puente, lo que provocó hilaridad. O bien, la autora recuerda el sentido onomatopéyico, la jitanjáfora que cobra sentido a partir de sus valores fónicos que se leen en conjunto: "Caputín - tin - tin, / esta noche va a llover, / caputín - tin - tin, / al amanecer" (Gamboa, 1962, p. 75).

Según el juicio de Andricaín y Rodríguez (1997), la verdadera poesía no sirve para nada, pues no enseña nada y carece de moralejas y no se escribe con un fin didáctico ni pedagógico, pero conforme con el principio de Martí, ayuda al ser humano a prepararse para la vida y así percibir sentimientos y conceptos que facilitan insertarse, de forma armónica y bella, en la existencia misma. Para estas personas autoras, la poesía permite crecer espiritualmente y humanizarse. pues, por medio de ella se nos permite decantar las emociones, anhelos o frustraciones de otras personas. Por eso, Gamboa ve el territorio de la poesía como una "tierra encantada" para percibir "las cosas sencillas: / el agua de cristal, / el cielo en un charquito, / la danza del viento / y los caballitos / de mar" (Gamboa, 1978, p. 28).

La educadora, como poeta, no solo retomó el folclor, el carácter lúdico o el sinsentido, sino que también ofreció poemas narrativos que, sin perder su carácter metafórico y el ritmo, pueden leerse e interpretarse como un cuento, tal como lo explican Bornemann (1977) y Andricaín y Rodríguez (1997). Se encuentra una muestra de ello en el poema Hormiguita (1932), en el que como ya se expresó, hace una recreación del cuento popular recogido por la escritora andaluza Fernán Caballero y del que presentó otra versión con el título "Hormiguita y Ratón Pérez" en el libro Paco y Lola (1960b), el poema El sombrero aventurero de la niña Rosaflor (1969), en el que se narran las peripecias de una niña por rescatar el sombrero que le arrancó 
el viento, o "Cómo vinieron al mundo Peluso, Pelusín y Pelusillo", incluido en el libro La casita del monte (1973), en el que se narra el advenimiento a la vida de tres pajarillos.

Emma Gamboa también considera la acción dramática en algunos de sus poemas, de tal manera que la niña o el niño, al decirla en voz alta, realice alguna acción corporal o establezca un diálogo que puede ser representado en un escenario, tal como recomienda Pellizzari (2021), hecho aunado, por supuesto, a la propuesta de la autora de realizar actos de poesía coral, como una tradición escolar que ella recibió, en sus primeros años de formación docente bajo la tutela de intelectuales de la talla de Omar Dengo, Carmen Lyra o Roberto Brenes Mesén. La autora estableció así los parlamentos de cada personaje:

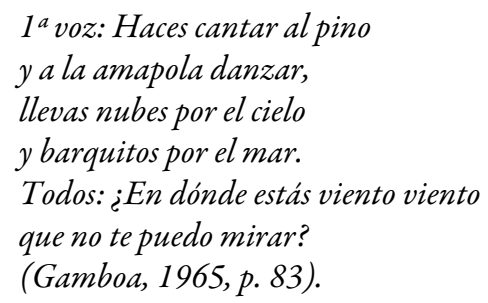

Conforme con esta visión optimista y esperanzadora, Emma Gamboa recomienda, por medio de la lectura de sus libros, a que la poesía ingrese en la escuela, propuesta que aún en su época podía considerarse revolucionaria, pues, tal como lo consideraba el maestro uruguayo Jesualdo (1967), la poesía había sido desterrada de la institución educativa y fue relegada a ser usada como una herramienta más para la enseñanza al priorizar su carácter utilitario, en algunos casos como un auxiliar moralista. La profesora costarricense, al igual que este maestro sudamericano, abogan por el sensible fulgor de las palabras, la magia, los sonidos o los símbolos y destaca el papel de docentes de educación preescolar y primaria que sientan "la música de las palabras y logran transmitirlas a los niños hacen florecer sentimientos finos, tendencias e intuiciones artísticas" (Gamboa, 1960a, p 12).

$\mathrm{Al}$ igual que Tagore (s.f.), quien señaló que su manera de mirar el mundo sería muy diferente si no hubiera leído en su niñez obras como Lasmily una noches o cuentos de hadas, Gamboa trae a la memoria la infancia del escritor ruso Máximo Gorki, quien se mantuvo, con firmeza, en su credo de "luz salvadora" (Gamboa, 1965, p. 82), a pesar de las miserias y experiencias rudas que vivió en su infancia con personas que no le brindaron comprensión, si su abuela no le hubiera otorgado el arte del poema. Ha de ser por eso que esta educadora insistió en que el magisterio llevara la poesía a la niñez como una fuente que preservara su ingenuidad y frescura a través de los siglos.

Tampoco puede perderse de vista que la propia Emma Gamboa sintió ese influjo de la poesía gracias a su maestra de primeras letras, evocada en el poema "La niña Oliva", guardado en su libro Instante de la rosa (1977) y buscó ese mismo sentir para las jóvenes generaciones, pues, como lo describe Calvo (2015), en las experiencias de niñez de poetas se encuentran elementos comunes como "el gozoso sonido de las palabras, un cosquilleo interior, el sentimiento de estar ante algo nuevo y removedor pero que, al mismo tiempo, reconocemos como muy antiguo y muy nuestro" (p. 36).

Se pronunciaba Gamboa a favor de un encuentro diáfano y armónico entre la niñez y la literatura, en el que no se recurriera a fragmentos de lecturas inconexas ni tediosos textos elaborados con simple intención didáctica ni caer en rutinarios análisis que podrían compararse con la metáfora de masticar un manjar masticado, de manera automática, como lo haría un rumiante. Por eso se refería a la novela Cocorí, de Joaquín Gutiérrez, como un libro que reúne los atributos propios de la mejor literatura infantil, pues posee "equilibrio: fuerza telúrica contrastada con ingenio, intrepidez, asombro y ternura. Naturaleza y humanidad” (Gamboa,1973, p. 16A). Además, recomienda a las madres leer un libro encantador por las noches, y a profesionales de la educación dedicar alguna hora de la semana a la lectura de un encantador cuento. 
Es que ese encuentro edificante con la poesía es también una manera de apropiarse de la libertad, pues, a la luz de los postulados de Dewey que Emma Gamboa (1958) difundió y defendió, la libertad es fin último y primordial de la educación, por esa razón, en su crítica del libro Fábula del bosque, de Fernando Centeno Güell, Gamboa (1975) reafirma su confianza en la libertad poética, tanto en su decir como su forma. Por tanto, esa ruptura con preceptos y ataduras también es sentida por quienes leen la poesía. Razón por la cual escribe en su versión libre de la canción de Hattie Summerfield: "Vamos a los prados / en alegre danza / a gozar la dicha / de la libertad." (Gamboa, s.f. p. 7).

Abogó Gamboa para que la niñez comprendiera, sintiera y memorizara la poesía, y la representara en actos públicos, pues, de esa forma, podría interiorizar sentimientos profundos. Invitaba a escolares a expresarse de manera espontánea, sin caer en la exageración ni la monotonía. La memorización poética es una tradición antigua, tal como apunta Vallejo (2020): "A todos nos hicieron aprender poemas en la escuela y ahora, pasados los años, después de haber olvidado tantas cosas, recordamos que aún los recordamos con asombrosa nitidez" (p. 101), y manifiesta, en el marco de la mitología griega, a la diosa Mnemosine, que es madre de las musas y de su nombre proviene la palabra mnemotecnia, como personificación misma del recuerdo. Es la memoria también aliada del ritmo, la cadencia, la danza, la música y el juego de la repetición, placeres necesarios para sobrellevar la existencia.

Al hacer esa valoración del ritmo y la memoria, Pellizzari (2021) comparó un poema con una orquesta polifónica, concebida como un conjunto de sonidos simultáneos que se integran en un todo armónico, pues, como si se tratara de diferentes instrumentos, se combinan vocales y consonantes con el fin de lograr la armonía: es una oración de la belleza. Ese sentido espiritual, décadas antes, fue rescatado por Gamboa (1960a), pues afirmó que "las letras y el arte son estériles si no están inspiradas por valores espirituales", (p. 14) ya que ante todo debe orientar a la persona a la ética del trato humano y a descartar el encono, la maledicencia o el irrespeto. Sin caer en la moraleja fácil ni en la enseñanza explícita, la maestra convidó a ese sentir fraterno: "En el alba todo es paz, / todo es luz y amor. / Es el alba. / -Buenos días, señor. // En el alba / nos saluda Dios" (Gamboa, 1980, p. 7).

En su poesía, Gamboa afirmó en una entrevista (No estamos mal en literatura infantil, 1975), se resguarda la tesis de orientar a la niñez a la apreciación y asimilación del universo, pues se deben colocar valores y principios complicados de tal manera que puedan ser fácilmente comprendidos, con respeto absoluto a su vocabulario elemental, sin perder nunca el sentido estético. Explicó que no se puede comprender la belleza de los pájaros sin lograr la integración del mundo de las aves. Dice, de manera rotunda: "No quise dar moraleja, sino explicar" ( No estamos mal en literatura infantil, 1975, p. 4C).

Jubilada, en la etapa de madurez, la educadora costarricense afirmaba que la enseñanza debería ser como un poema, pues sin una visión estética no es posible lograr el interés ni la simpatía en la niñez. En la entrevista publicada en el diario La Nación, Gamboa declaró que "el despertar de los niños no se haga sin recurrir a la magia de lo bello" ( No estamos mal en literatura infantil, 1975, p. 4C), pues así se podría afrontar la crisis de valores del país y luchar por la dignidad y la honradez perdidas.

Razones sobran para revalorar la lectura de la poesía de Emma Gamboa en los hogares y las escuelas costarricenses. Debe tomarse en cuenta que se publicó Flor de infancia, su último libro dedicado a la niñez, de manera póstuma en 1978 y que su visión de armonía y encuentro con la naturaleza se vuelven necesarios en el siglo XXI. A pesar de que, poco tiempo antes de su fallecimiento, en esa entrevista (No estamos mal en literatura infantil, 1975) aseverara que durante toda su vida se había entregado con pasión a la enseñanza y que no había podido dedicarse, como hubiera querido, a la literatura. Su reivindicación como escritora se vuelve necesaria en las letras costarricenses, pues es necesario aspirar a que la humanidad pueda unirse en un corro, como lo soñara con la paráfrasis del poema de Paul Fort: "La ronda crecida y hermosa / los hombres tendrían que mirar / y unirían sus manos amigas / en todas las tierras y el mar” (Gamboa, 1978, p. 22). 


\section{Referencias bibliográficAs}

Andricaín, S. y Rodríguez, A. O. (1997). Escuela y poesía. ¿Y qué hago con el poema? Magisterio.

Aramburu, J. (1944). El folklore de los niños. Editor El Ateneo.

Bornemann, E. (1977). Poesía infantil, estudio y antología. Editorial Latina.

Caballero, F. (1988). Cuentos de encantamiento. Espasa - Calpe, Planeta - Agostini.

Calvo, M. (2015). Tomar la palabra, la poesía en la escuela. Fondo de Cultura Económica.

Chase, A. (1988). Cultivo una rosa blanca. Editorial Costa Rica.

Dengo, M. E. (2011). Tierra de maestros. Editorial Universidad de Costa Rica.

Dengo, O. (1961). Escritos y discursos. Ministerio de Educación Pública.

Dobles, M. (1991). Por quécuento y canto para mis niños. Editorial Costa Rica.

El Ejecutivo se comprometió a dar impulso a las Bibliotecas Escolares. (1954, 17 de abril). Diario de Costa Rica,1, 4.

Ferrero, L. (1958). Literatura infantil costarricense. Ministerio de Educación Pública.

Gamboa, E. (s.f.). Canciones para niños. Colección Lehmann.

Gamboa, E. (1932, 19 de julio). Hormiguita. Repertorio Americano (Tomo 25), 14(593), 16.

Gamboa. E. (Comp.). (1941). Versos para niños. Colección Lehmann.

Gamboa, E. (1953, abril). Martí. Farolito, 2(9), 5.

Gamboa. E. (1954, 5 de setiembre). El libro debe estar al alcance de todos. La Nación, p. 10.

Gamboa, E. (1954, octubre, 1954). Gracielina. Farolito, 3(3), 7-9.

Gamboa, E. (1955, noviembre). San Nicolás y la niña que no se quería dormir. Farolito, 3(12), 12-14.

Gamboa, E. (1956, marzo). Don Juanito. Farolito, 3(13), 5-9.

Gamboa, E. (1957, febrero). Gabriela Mistral en Costa Rica, un recuerdo. Brecha, 1(6), 5.

Gamboa, E. (1958). John Dewey y una filosofia de la libertad. Trejos Hnos.

Gamboa, E. (1958, 22 de noviembre). Don Joaquín. La Nación, p. 4.

Gamboa, E. (1960a, 11 de octubre). Letras y arte de la educación son estériles si no están inspiradas por valores espirituales superiores. La Nación, p. 14.

Gamboa, E. (1960b). Paco y Lola. Colección Lehmann.

Gamboa, E. (1965, Febrero - Marzo). Poesía coral. Revista de la Asociación Nacional de Educadores (ANDE), 7(12), 82-83.

Gamboa, E. (1969). El sombrero aventurero de la niña Rosaflor. Casa Gráfica.

Gamboa, E. (1971). Omar Dengo. Ministerio de Cultura, Juventud y Deportes.

Gamboa, E. (1973, 19 de diciembre). “Cocorí, lectura de alta calidad”. Todo por una rosa. La Nación, p. 16 A.

Gamboa, E. (1975, 5 de febrero). Fábula del bosque. La Nación, p. 15.

Gamboa, E. (1977). Instante de la rosa. Editorial Costa Rica.

Gamboa, E. (1978). Flor de infancia. Editorial Costa Rica.

Gamboa, E. (1980). La casita del monte. (3ra edición). Editorial Costa Rica.

Gamboa, E. (1992). Conceptos de la Dra. Emma Gamboa sobre “Los cuentos viejos”. En M. Leal de Noguera (Autora), Cuentos viejos (p. 11). Editorial Costa Rica.

Gamboa de Murillo, O. (1990). Emma Gamboa y la Facultad de Educación. Educación, 14(1), 131-144. https://bit $. \operatorname{ly} / 3 \mathrm{gFNqEv}$

Jesualdo. (1967). La literatura infantil. (5ta edición). Editorial Losada.

La primera Feria del Libro ser ha interpretado en dimensiones nacionales. (1954, 25 de agosto). Diario Nacional, 1, 3.

Lars, C. (1987). Escuela de pájaros. RHD Editorial. 
Martí, J. (2010). La edad de oro. Editorial Pueblo y Educación.

Miretti, M. L. (2004). La literatura para niños y jóvenes. Homo Sapiens Ediciones.

Mistral, G. (1926). Desolación. (3ra edición). Nascimento.

Mistral, G. (2010). Gabriela Mistral en verso y prosa, antología. Real Academia Española y Asociación de Academias de la Lengua Española.

Mistral, G. (2011). Contar. En F. González, M. Soto y M. Oliva (Comps.). Toda Gabriela Mistral en Repertorio Americano (Tomo II) (pp. 229 - 231). Editorial Universidad Nacional.

No estamos mal en literatura infantil. (1975, 23 de marzo). La Nación, 4C.

Pellizzari, G. (2021). Una mirada a la poesía para la niñez. Academia Argentina de Literatura Infantil y Juvenil.

Rubio, C. (2021). Centenario de la Cátedra de Literatura Infantil en Costa Rica y el despertar de una literatura dirigida a la niñez. En V. Sánchez, M. Portilla, C.F. Monge, C. Rubio y E. Cartín de Guier (Autores) Voces de la Academia Costarricense de la Lengua (pp. 47 - 81). Academia Costarricense de la Lengua.

Tagore, R. (s.f.). Entre-visiones de Bengala. Plaza \& Janes.

Vallejo, I. (2020). El infinito en un junco. La invención de los libros en el mundo antiguo. (20va edición). Siruela.

Whitman, W. (1975). Walt Whitman. Ministerio de Cultura, Juventud y Deportes.

\section{INFORMACIÓN ADICIONAL}

Cómo citar: Rubio-Torres, C. (2022). El verso aventurero de Emma Gamboa, poesía infantil de la maestra, pedagoga y escritora. Revista Educación, 46(1). http://doi.org/10.15517/revedu.v46i1.49661

Agradecimiento: El autor agradece a la Dra. Ana Isabel Gamboa, sobrina nieta de la Dra. Emma Gamboa, su apoyo y colaboración. 